\title{
I n vitro evaluation of antioxidant potential of Artocarpus chama Buch. fruits
}

\author{
Taksim Ahmed $^{1 * \perp}$, Mohammad Nasir Uddin ${ }^{1 \perp}$, Shaikh Faisol Ahmed, Arindam Saha, Kaniz Farhana, and Md. Sohel \\ Rana. \\ ${ }^{1}$ College of Pharmacy, Chosun University, 375 Seosuk-dong, Gwangju 501-759, Republic of Korea. \\ ${ }^{2}$ Laboratory of natural products research, Department of pharmacy, Jahangirnagar University, Savar, Dhaka-1342, Bangladesh.
}

\section{ARTICLE INFO \\ Article history: \\ Received on: 10/10/2012 \\ Revised on: 18/10/2012 \\ Accepted on: 23/10/2012 \\ Available online: 28/10/2012}

\section{Key words:}

Artocarpus chama,

In vitro,

Antioxidant capacity,

DPPH radical,

Cupric reducing,

Reducing power.

\begin{abstract}
Phytochemicals possessing phenols and flavonoids are potential sources of antioxidants, which are useful to scavenge reactive oxygen species (ROS). The present study was undertaken to evaluate and compare the antioxidant potential of pet ether and methanol extracts of fruits of Artocarpus chama Buch., using DPPH (1,1-diphenyl-2-picrylhydrazyl) scavenging assay, cupric reducing antioxidant capacity, reducing power antioxidant capacity, determination of total phenol and flavonoid contents. Preliminary phytochemical study revealed the presence of alkaloid and flavonoid in both extracts. The fraction showed significant antioxidant activities in the assay compared to the reference ascorbic acid in a dose dependent manner. In DPPH radical scavenging assay, the $\mathrm{IC}_{50}$ value of the crude pet ether and methanol extract was $27.64 \mu \mathrm{g} / \mathrm{mL}$ and $39.08 \mu \mathrm{g} / \mathrm{mL}$, respectively, whereas $\mathrm{IC}_{50}$ value for the reference ascorbic acid was $12.70 \mu \mathrm{g} / \mathrm{mL}$. Furthermore, both extracts showed similar cupric reducing power and reducing power capability. In addition, pet ether extract contains higher amount of phenols as compared with methanol extract, and possess similar flavonoid content expressed as Gallic acid and Quercetin, respectively. Based on these findings, it can be concluded that pet ether extract of the fruits of A. chama Buch possesses significant antioxidant potential comparing with methanol extract, which may be attributed to the high amount of phenols and flavonoids present in the extract.
\end{abstract}

\section{INTRODUCTION}

Research interest in phytoceuticals to inhibit chronic diseases and aging is gathering momentum. Reactive oxygen species such as hydroxyl $\left(\mathrm{OH}^{\bullet}\right)$ and peroxyl radicals $\left(\mathrm{ROO}^{\bullet}\right)$ and the superoxide anion $\left(\mathrm{O}_{2}{ }^{\circ}\right)$ are constantly produced as a result of metabolic reactions in living systems (Halliwell and Gutteridge, 1990). Furthermore, our body is bombarded daily with health hazards and irritants in the form of air pollutants, synthetic drugs, cigarette smoke and food additives which in turn increases free radical production (Shailja et al., 2009). Living systems are protected from oxidative damage caused by these reactive species by enzymes such as superoxide dismutase and glutathione

\footnotetext{
$\perp_{\text {Both the authors contributed equally. }}$

* Corresponding Author

Taksim Ahmed

College of Pharmacy, Chosun University,

375 Seosuk-dong, Gwangju 501-759, Republic of Korea.

Tel.: +821055296067
}

peroxidase and antioxidant compounds such as ascorbic acid, tocopherols, and carotenoids (Sies, 1997). However, when freeradical production exceeds the antioxidant capacity of the organism, these radical species attack lipids, proteins, and DNA, thus damaging structural integrity and function of cell membranes, enzymes, and genetic material. A growing body of evidence indicates that various pathological conditions, including cardiovascular disease, arthritis, and various cancers are associated, at least in part, with the damaging effects of uncontrolled free-radical production (Byers and Perry, 1992). Recent research on free radicals has confirmed that foods, rich in antioxidants play an essential role in the prevention of cardiovascular diseases and cancers (Kris-Etherton et al., 2002, Serafini et al., 2002) and neurodegenerative diseases, including Parkinson's and Alzheimer's diseases (Di Matteo et al., 2002), as well as Inflammation and problems caused by cell and cutaneous aging (Ames et al., 1993). 
Therefore, profound interest has been grown on plant materials to find promising compound having antioxidative potential. Recently, a number of natural compounds such as polyphenols and flavonoids have been reported as antioxidants, which entrap and deactivate damaging ROS and RNS (Pietta, 2000; Hossain et al., 2006). Furthermore, they also possess antiinflammatory, antiviral and anticancer properties (Di Pietro et al., 2002; Barron et al., 2002). Artocarpus chama Buch. synonym A. chaplasha Linn., locally known as 'Chamfol' in Bangladesh, is a tall deciduous tree of the Moraceae family, grows all over the south asian region. It is generally used as timber for commercial purpose. Triterpenoids were found in the bark of A. chaplasha Linn. (Mahato et al., 1967). The juice of stem bark (5-10 mL, 3-4 times daily) is given orally in the treatment of diarrhea (Hemanta et al., 2001). However, Artocarpus species (Moraceae) provide a variety of prenylated flavonoids and a limited number of stilbenoids with interesting biological activities, such as cytotoxicity, antibacterial effects against cariogenic bacteria, and cyclooxygenase and tyrosinase inhibitory activities (Nomura et al., 1998; Soekamto et al., 2003; Su et al., 2002; Likhitwitayawuid and Sritularak, 2001; Likhitwitayawuid et al., 2000). Five new isoprenylated flavones, artochamins A-E, along with eight known flavones, were isolated from the roots of Artocarpus chama. (Yong-Hong et al., 2004). Furthermore, two new prenylated stilbenes, artochamins $\mathrm{F}$ and $\mathrm{G}$, and their four novel derivatives, artochamins $\mathrm{H}-\mathrm{K}$, were isolated from the stems of Artocarpus chama. (Yong-Hong et al., 2006). In addition, two new stilbenes with two isoprenoid groups, namely artostilbenes $\mathrm{A}$ and $\mathrm{B}$, were isolated from the stems of Artocarpus chama Buch (Yong-Hong et al., 2007). As per as our literature survey could ascertain, in vitro antioxidant activities of the A. chama fruits have not previously been published. In this study, we examined the antioxidant activity of crude pet ether and methanol extracts, employing various in vitro assay systems, such as the DPPH (1,1-diphenyl-2picrylhydrazyl) scavenging assay, cupric reducing antioxidant capacity, reducing power antioxidant capacity and determination of total phenolic and flavonoid content, in order to understand the usefulness of this plant as a functional food as well as in medicine.

\section{MATERIALS AND METHODS}

\section{Chemicals}

DPPH (1, 1-diphenyl, 2-picrylhydrazyl) was purchased from Sigma Chemical Co., USA, Potassium Fericyanide $\left[\mathrm{K}_{3} \mathrm{Fe}(\mathrm{CN})_{6}\right]$ from Loba Chemie Pvt. Ltd., Mumbai, India, Ascorbic acid from SD Fine Chem. Ltd., Biosar, India and Neocaproin $\left(\mathrm{C}_{14} \mathrm{H}_{12} \mathrm{~N}_{2}\right)$, Ammonium Molybdate, Folin-ciocalteun phenol reagent, Gallic acid $\left(\mathrm{C}_{7} \mathrm{H}_{6} \mathrm{O}_{5} \cdot \mathrm{H}_{2} \mathrm{O}\right)$, Quercetin were purchased from Merck, Germany.

\section{Plant material}

Artocarpus chama fruits were collected from Jahangirnagar University, Savar, Dhaka, Bangladesh, in May 2009 while the fruits were matured but unripe and identified by the taxonomist of the National Herbarium of Bangladesh, Mirpur, Dhaka, Bangladesh. A voucher specimen of the plant has been deposited (Accession No.: 35650) in the herbarium for further reference.

\section{Preparation of plant extract}

Powdered dried fruits (100 g) were macerated with $70 \%$ pet ether and $70 \%$ methanol, $500 \mathrm{~mL}$ each, with occasional stirring at $25 \pm 2{ }^{\circ} \mathrm{C}$ for 3 days. The extracts were then filtered using a Buchner funnel and a sterilized cotton filter. The solvent was completely removed by rotary evaporator and $12.5 \mathrm{~g}$ pet ether and $10.8 \mathrm{~g}$ methanol extracts were obtained. These crude extracts were used for investigation of antioxidative potential.

\section{Preliminary phytochemical screening}

The freshly prepared crude extracts were qualitatively tested for the presence of chemical constituents. Phytochemical screenings of the extracts were performed using the following reagents and chemicals; alkaloids with Dragendroff's reagents, flavonoids with the use of $\mathrm{Mg}$ and $\mathrm{HCl}$; tannins with ferric chloride and potassium dichromate solutions and saponins with ability to produce stable foam and steroids with LibermannBurchard reagent. Gum was tested using Molish reagent and concentrated sulfuric acid; reducing sugars with Benedict's reagent. These were identified by characteristic color changes using standard procedures by Ghani, 2005.

\section{Tests for antioxidant activity}

\section{DPPH free radical scavenging activity}

The free radical scavenging activity of the extracts, based on the scavenging activity of the stable 1, 1-diphenyl-2picrylhydrazyl (DPPH) free radical, was determined by the method described by Braca et al., 2001. Plant extract $(0.1 \mathrm{~mL})$ was added to $3 \mathrm{~mL}$ of a $0.004 \%$ ethanol solution of DPPH. Absorbance at $517 \mathrm{~nm}$ was determined after $30 \mathrm{~min}$ and the percentage inhibition activity was calculated from $\left[\left(A_{o}-A_{1}\right) / A_{o}\right] \times 100$, where $A_{o}$ is the absorbance of the control (DPPH solution) and $A_{1}$ is the absorbance of the extract/standard. The inhibition curves were prepared and $\mathrm{IC}_{50}$ values were calculated.

\section{Cupric reducing antioxidant capacity}

The cupric reducing antioxidant activity of the pet ether and methanol extracts were determined by the method described by Resat et al., 2004. Different concentrations of the extract (5$200 \mu \mathrm{g}$ ) in $0.5 \mathrm{~mL}$ of distilled water were mixed with Cupric Chloride $(1 \mathrm{~mL}, 0.01 \mathrm{M})$, Ammonium acetate buffer $(1 \mathrm{~mL}, \mathrm{pH}$ 7.0), Neocaproin $(1 \mathrm{~mL}, 0.0075 \mathrm{M})$ and finally distilled water $(0.6$ $\mathrm{mL}$ ). The mixture was incubated for 1 hour at room temperature. Then the absorbance of the solution was measured at $450 \mathrm{~nm}$ against blank. Distilled water $(0.5 \mathrm{~mL})$ in the place of extract is used as the blank. The molar absorptivity of the Cuprac method for each antioxidant was found from the slope of the calibration line concerned. Ascorbic acid was used as the standard solution. 


\section{Reducing power antioxidant capacity}

The reducing power was determined according to the method previously described by Oyaizu, 1986. Different concentrations of extracts $(25-500 \mu \mathrm{g})$ in $1 \mathrm{~mL}$ of distilled water were mixed with phosphate buffer $(2.5 \mathrm{~mL}, 0.2 \mathrm{M}, \mathrm{pH}$ 6.6) and potassium ferricyanide $\left[\mathrm{K}_{3} \mathrm{Fe}(\mathrm{CN})_{6}\right](2.5 \mathrm{~mL}, 1 \%)$.

The mixture was incubated at $50^{\circ} \mathrm{C}$ for $20 \mathrm{~min}$. An aliquot $(2.5 \mathrm{~mL})$ of trichloroacetic acid $(10 \%)$ was added to the mixture, which was then centrifuged at $3000 \mathrm{rpm}$ for $10 \mathrm{~min}$. The supernatant $(2.5 \mathrm{~mL})$ was mixed with distilled water $(2.5 \mathrm{~mL})$ and $\mathrm{FeCl}_{3}(0.5 \mathrm{~mL}, 0.1 \%)$ and the absorbance was measured at 700 $\mathrm{nm}$. Increased absorbance of the reaction mixture indicated increased reducing power. Ascorbic acid was used as the reference.

\section{Determination of total phenol content}

The total phenolic content of plant extracts were determined using Folin-Ciocalteu reagent (Yu et al., 2002). Plant extracts $(100 \mu \mathrm{L})$ were mixed with $500 \mu \mathrm{L}$ of the Folin-Ciocalteu reagent and $1.5 \mathrm{~mL}$ of $20 \%$ sodium carbonate.

The mixture was shaken thoroughly and made up to 10 $\mathrm{mL}$ using distilled water. The mixture was allowed to stand for 2 hour. Then the absorbance at $765 \mathrm{~nm}$ was determined. These data were used to estimate the phenolic contents using a standard curve obtained from various concentration of gallic acid.

\section{Determination of total flavonoid content}

The content of flavonoid compounds in both the extracts was determined by the method described by Chang et al., 2002 . $1.0 \mathrm{~mL}$ of extract was mixed with methanol $(3 \mathrm{~mL})$, aluminium chloride $(0.2 \mathrm{~mL}, 10 \%)$, potassium acetate $(0.2 \mathrm{~mL}, 1 \mathrm{M})$ and distilled water $(5.6 \mathrm{~mL})$ and incubated the mixture for $30 \mathrm{~min}$ at room temperature. Then the absorbance was measured at $415 \mathrm{~nm}$ against blank. Methanol $(1 \mathrm{~mL})$ in the place of extract was used as the blank and Quercetin was used as the standard solution. All determinations were carried out in triplicates. The amount of flavonoids in plant extracts in Quercetin equivalents $(\mathrm{QE})$ was calculated by the following formula: $\mathrm{X}=(\mathrm{A} \times \mathrm{m} 0) /\left(\mathrm{A}_{0} \times \mathrm{m}\right)$, where $\mathrm{X}$ is the flavonoid content, $\mathrm{mg} / \mathrm{mg}$ plant extract in $\mathrm{QE}, \mathrm{A}$ is the absorption of plant extract solution, $\mathrm{A}_{0}$ is the absorption of standard rutin solution, $\mathrm{m}$ is the weight of plant extract in $\mathrm{mg}$ and $\mathrm{m} 0$ is the weight of Quercetin in the solution in $\mathrm{mg}$.

\section{Statistical analysis}

The results were expressed as means \pm Standard deviation (SD) from triplicate experiments and evaluated with the analysis of student's t-test. Differences were considered significant at a level of $\mathrm{P}<0.05 . \mathrm{IC}_{50}$ was calculated using SigmaPlot 11 software.

\section{RESULTS AND DISCUSSION}

\section{Preliminary phytochemical screening}

The preliminary phytochemical screening revealed that the extracts possess the presence of various bioactive components like flavonoids, alkaloids and carbohydrates (Table 1).

\section{$\mathrm{DPPH}^{-}$radical scavenging activity}

In DPPH radical scavenging assay, as shown in Fig.1, both pet ether and methanol extract exhibited a concentrationdependent antiradical activity by inhibiting $\mathrm{DPPH}^{-}$radical. Ascorbic acid, which is a well known antioxidant, showed higher degree of free radical-scavenging activity than that of the plant extract at each concentration points. The $\mathrm{IC}_{50}$ value of the crude pet ether and methanol extract were $27.64 \mu \mathrm{g} / \mathrm{mL}$ and 39.08 $\mu \mathrm{g} / \mathrm{mL}$, respectively, while the $\mathrm{IC}_{50}$ value for the reference ascorbic acid was $12.70 \mu \mathrm{g} / \mathrm{mL}$. The DPPH antioxidant assay is based on the ability of 1,1-diphenyl-2-picryl-hydrazyl (DPPH), a stable free radical, to decolorize in the presence of antioxidants (Kumarasamy et al., 2007). The method is based on the reduction of ethanolic $\mathrm{DPPH}^{-}$solution in the presence of a hydrogen donating antioxidant, due to the formation of the non-radical form DPPH-H by reaction. The extracts were able to reduce DPPH radical (visible deep purple color) to the yellow-coloured diphenylpicrylhydrazine. It has been found that cysteine, glutathione, ascorbic acid, tocopherol, polyhydroxy aromatic compounds (e.g. hydroquinone, pyrogallol, gallic acid), and aromatic amines (e.g. p-phenylene diamine, p-aminophenol), reduce and decolorise 1,1-diphenyl-2-picrylhydrazyl by their hydrogen donating ability (Blois, 1958). Therefore, one of the possible mechanism of the pet ether extract's better antioxidant capacity in comparing with methanol extract might be the resultant of containing good amount of phenolic compounds, which shows antioxidant activity due to their redox properties, play an important role in absorbing and neutralizing free radicals, quenching single and triple oxygen or decomposing peroxide.

Table. 1: Result of phytochemical screening of pet ether and methanol extracts of the fruits of Artocarpus chama Buch.

\begin{tabular}{|c|c|c|c|c|c|c|c|c|}
\hline Extract & Carbohydrate & Glycoside & Glucoside & Alkaloid & Saponin & Steroid & Flavonoid & Tannin \\
\hline ACFM & + & - & - & + & - & - & $+/-$ & - \\
\hline
\end{tabular}

ACFP: Artocarpus chama fruits pet ether; ACFM: Artocarpus chama fruits methanol, (+): Present; (-): Absent

Table. 2: Total phenol and total flavonoid contents of pet ether \& methanol extracts of the fruits of Artocarpus chama Buch

\begin{tabular}{ccc} 
Extract & Total phenol (in $\mathbf{~ m g / g}$, Gallic acid equivalents) & Total flavonoid (in mg/g, Quercetin equivalents) \\
ACFP & $178.08 \pm 2.05$ & $24.95 \pm 0.36$ \\
ACFM & $41.12 \pm 1.83$ & $25.71 \pm 0.59$ \\
\hline
\end{tabular}

Values are the average of triplicate experiments and represented as mean \pm SD. 


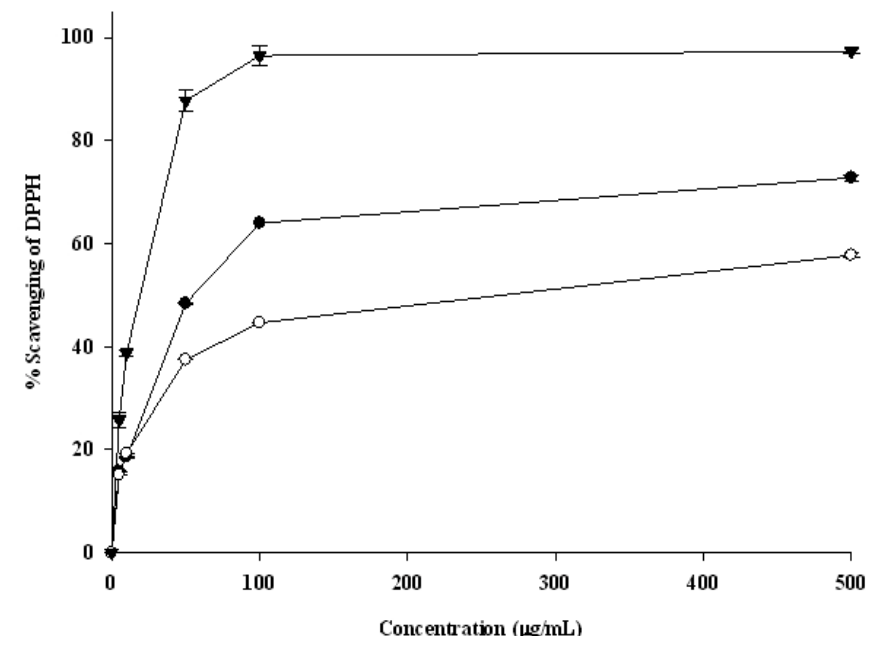

Fig. 1: DPPH radical scavenging activity of pet ether $(\bullet)$ and methanolic (०) extracts of the fruits of Artocarpus chama Buch along with the standard Ascorbic acid $(\boldsymbol{\nabla})$. (Mean \pm SD,$n=3$ )

\section{Cupric reducing antioxidant capacity (CUPRAC)}

The reducing ability of a compound generally depends on the presence of reductants (Pin-Der et al., 1999), which have been reported to exhibit antioxidative potential by breaking the free radical chain, donating a hydrogen atom (Gordon, 1990). The CUPRAC method of reducing antioxidant capacity assay uses bis(2,9-dimethyl-1,10 phenanthroline: neocuproine) $\mathrm{Cu}$ (II) chelate cation as the chromogenic oxidant, which is reduced in the presence of n-electron reductant antioxidants to the cuprous neocuproine chelate $[\mathrm{Cu}(\mathrm{I})-\mathrm{Nc}]$ showing maximum light absorption at $450 \mathrm{~nm}$. Colour development in the CUPRAC method is based on the following reaction:

$$
\begin{aligned}
\mathrm{n}-\mathrm{Cu}(\mathrm{Nc})_{2}{ }_{2}+ & +\mathrm{n} \text {-electron reductant }(\mathrm{AO}) \leftrightarrow \mathrm{nCu}(\mathrm{Nc})_{2}{ }^{+}+\mathrm{n}- \\
& \text { electron oxidized product }+\mathrm{n} \mathrm{H}^{+}
\end{aligned}
$$

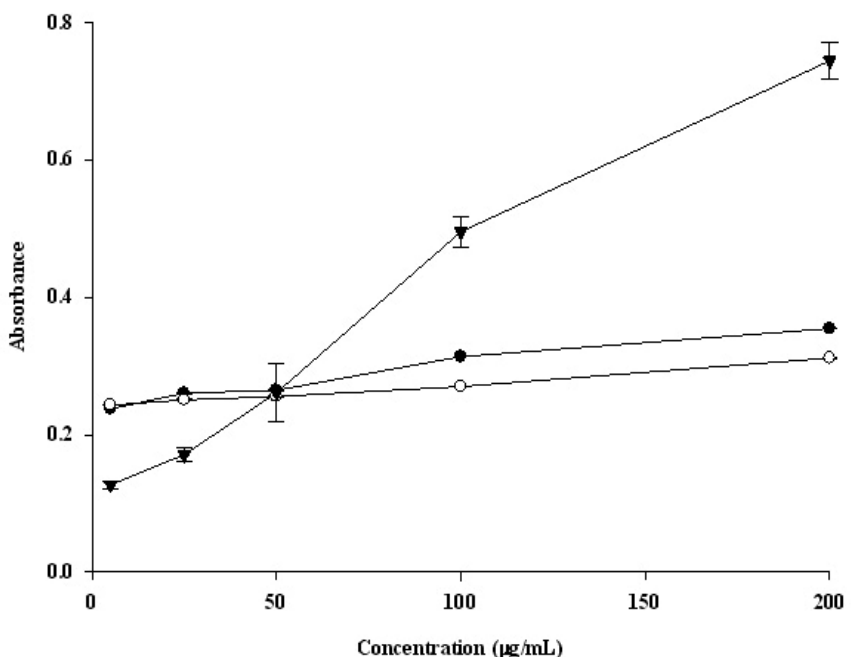

Fig. 2: Cupric reducing power of pet ether $(\bullet)$ and methanolic $(\circ)$ extracts of the fruits of Artocarpus chama Buch. along with the standard Ascorbic acid $(\boldsymbol{\nabla})$. (Mean $\pm \mathrm{SD}, \mathrm{n}=3)$

Where, the electrons required for the formation of the $\mathrm{Cu}$ (I)-Nc chromophore are donated by the tested antioxidants. In this reaction, the reactive Ar-OH groups of polyphenolic antioxidants are oxidized to the corresponding quinones $(\mathrm{Ar}=\mathrm{O})$ (ascorbic acid is oxidized to dehydroascorbic acid) and $\mathrm{Cu}$ (II)- $\mathrm{Nc}$ is reduced to the highly colored $\mathrm{Cu}$ (I)-Nc chelate (Resat et al., 2008; Reşat et al., 2007). As observed from Fig. 2, at concentration level of 200 $\mu \mathrm{g} / \mathrm{mL}$, the reducing capacity of pet ether, methanol extract and ascorbic acid is $0.3115,0.3545$ and 0.744 , respectively. According to changed concentration trend, we concluded that the reducing power of extracts were lower than that of ascorbic acid. The probable mechanism of Cupric reducing power of extracts, would be the resultant of having a good number of polyphenolics and flavonoids, as the reactive hydroxyl groups of polyphenolics, oligomeric flavonoids, is oxidized with the CUPRAC reagent to the corresponding quinines (Resat et al., 2004).

\section{Reducing power antioxidant capacity}

Fig. 3 shows the reducing power capabilities of the plant extracts compared to ascorbic acid. Both extracts displayed good reducing power which was found to rise with increasing concentrations of the extracts. At $200 \mu \mathrm{g} / \mathrm{mL}$ concentration level, the absorbance of standard ascorbic acid, pet ether extract and methanol extract was 1.01, 0.52 and 0.60 , respectively. Both the plant extracts showed almost similar reducing power capacity. In reducing power assays, the presence of antioxidants in the fruits can reduce the oxidized form of iron $\left(\mathrm{Fe}^{3+}\right)$ to its reduced form $\left(\mathrm{Fe}^{2+}\right)$ by donating an electron. Thus, it can be assumed that the presence of reductants (i.e. antioxidants) in A. chama extracts causes the reduction of the $\mathrm{Fe}^{3+}$ /ferricyanide complex to the ferrous form. Therefore, the $\mathrm{Fe}^{2+}$ complex can be monitored by measuring the formation of Perl's Prussian blue at $700 \mathrm{~nm}$. A higher absorbance indicates greater reducing power ability (Gordon, 1990).

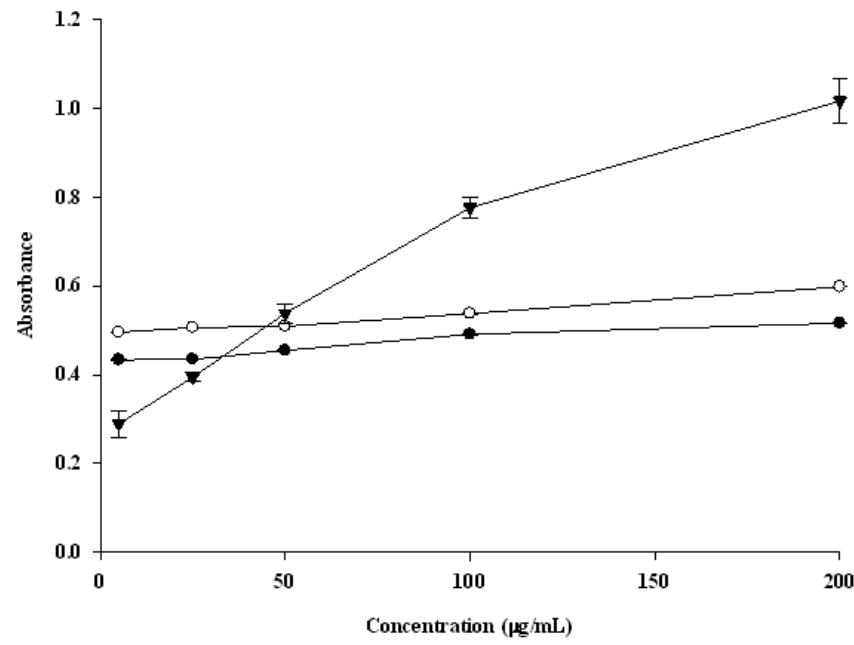

Fig. 3: Reducing power of pet ether $(\bullet)$ and methanolic $(\circ)$ extracts of the fruits of Artocarpus chama Buch. along with the standard Ascorbic acid ( $\nabla)$. (Mean $\pm \mathrm{SD}, \mathrm{n}=3$ ).

\section{Determination of total phenol content}

Several reports have conclusively shown close relationship between total phenolic content and antioxidative 
activity of the fruits and vegetables. Phenolic compounds, as natural antioxidants exhibit therapeutic potential in multiple diseases including cardiovascular disease, aging and cancer (Vinson et al., 1998). It has been reported that phenolic compounds with ortho- and para-dihydroxylation or a hydroxy and a methoxy group are more effective than simple phenolics (Frankel et al., 1995). Moreover, the antioxidant activity of phenolic compounds is mainly due to their redox properties, which can play an important role in adsorbing and neutralising free radicals, quenching singlet and triplet oxygen, or decomposing peroxides (Uritani et al., 1994). However, the pet ether extract of the fruits of A. chama Buch. was found to contain large amount of phenolics, $178.08 \pm 2.05 \mathrm{mg} / \mathrm{g}$ Gallic acid equivalent(GAE) while methanolic extract contain moderate amount, $41.12 \pm 1.83 \mathrm{mg} / \mathrm{g}$ GAE using Folin-Ciocalteau method. The results were represented in Table 2. As the exact chemical nature of the FolinCiocalteu reagent is not known, but it is believed to contain heteropolyphosphotunstates molybdates. Sequences of reversible 1 or 2 electron reduction reactions lead to blue species, possibly $\mathrm{PMoW}_{11} \mathrm{O}_{40}$ (Yu et al., 2002).

Furthermore, stilbenes are naturally occuring polyphenolic compounds which have been found in many families of higherplants, such as Vitaceae, Gnetaceae, Polygonaceae, Liliaceae, Moraceae and Cyperaceae (Teguo and Fauconneau, 1998; Li and Wang, 2001). Since stems of A. chama contains stilbenes, one other possible mechanism of antioxidant activity might be the presence of stilbenes in A. chama fruits, thus further extensive studies following structural elucidation is required to evaluate the various pharmacological properties other than antioxidant properties of stilbenes.

\section{Determination of total flavonoid content}

Flavonoids, the main class of polyphenols in plants, are known to be antioxidants and free radical scavengers having the basic structure of diphenylpyrans. The antioxidative activities of flavonoids are multifaceted. Most flavonoids possess the ability to scavenge free radicals by acting as hydrogen as well as electron donors. Some flavonoids can also act as antioxidant by direct reaction with radicals to form less reactive products, and some species possess a capacity to chelate transition elements. Some flavonoids have been found to possess not only anti-inflammatory, antibacterial, antiviral, antiallergic, and antitumor activities but also been reported to possess antioxidant, antiradical properties as well as inhibit the activities of an array of enzymes such as xanthine oxidase (Pietta et al., 2000). Flavonoids possess phenolic hydrogens responsible for the radical scavenging activity. It has been reported that the $O$-dihydroxyl (catechol) structure in the B ring is the obvious radical target site for all flavonoids. The additional presence of both 3 and 5-hydroxyl groups is responsible for maximal radical scavenging potentials and strongest radical absorption (Feng et al., 1998). Flavonoids can exhibit their antioxidant activity in several ways: (i) Radical scavenging activity toward either reactive species (e.g. reactive oxygen species: ROS) such as $. \mathrm{OH}, \mathrm{O}_{2}{ }^{-}, \mathrm{O}_{2}$, or toward lipid peroxidizing radicals such as R; RO., and ROO. radical scavenging action generally proceeds via hydrogen atom transfer or electron donation; (ii) prevention of the transition metal-catalyzed production of reactive species (i.e. via Fentontype reactions) through metal chelation; (iii) interaction with other antioxidants (such as cooperative actions), localization, and mobility of the antioxidant at the microenvironment (Bombardelli et al., 1993). However, total flavonoid content of A. chama. fruits extracts is shown in Table 2.

The results were exhibited as Quercetin equivalent of flavonoids per gm of extracts of the sample. The total flavonoid content of pet ether and methanol extracts were found to be 24.95 \pm 0.36 and $25.71 \pm 0.59 \mathrm{mg} /$ quercetin equivalent, respectively. These results suggested that the antioxidant activities of $A$. chama might be due to its flavonoid content since $A$. chama roots contains a variety of prenylated flavonoids e.g. isoprenylated flavones, flavones (Yong-Hong et al., 2004).

\section{CONCLUSION}

The study clearly indicates that the pet ether and methanol extract have the significant amount of antioxidants. This might be rationale behind the using of this plant extract as folk medicine. Since the chemical composition and structures of active extract components are important factors governing the efficacy of natural antioxidants, the extract of Artocarpus chama Buch. needs their characterization. Therefore, further research is necessary for elucidating the active principles e.g. phenolic compounds and also in vivo studies are needed for understanding their mechanism of action as an antioxidant.

\section{REFERENCES}

Ames BN, Shigenaga MK, Hagen TM. Oxidants, antioxidants, and the degenerative diseases of aging. Proc Natl Acad Sci (USA) 1993; 90: 7915-22.

Barron D, Di Pietro A, Dumontet C, McIntosh DB. Isoprenoid flavonoids are new leads in the modulation of chemoresistance. Phytochem Rev 2002; 1: 325.

Blois MS. Antioxidant determinations by the use of a stable free radical. Nature 1958; 181: 1199-200.

Bombardelli, E., Morazzoni, P. The Flavonoids: New Perspectives in Biological Activities and Therapeutics. Chimicaoggi 1993; 25-28.

Braca, A., N.D. Tommasi, L.D. Bari, C. Pizza, M. Politi and I. Morelli. Antioxidant principles from Bauhinia terapotensis. J. Natl. Prod. 2001; 64: 892-5.

Byers, T., Perry, G. Dietary Carotenes, Vitamin C, and Vitamin E as protective antioxidants in human cancers. Annu. Rev. Nutr. 1992; 12: 139-159.

C. Chang, M. Yang and H. Wen. Cheru J. Estimation of total flavonoids content in propolis by two complementary colormetric methods. J. Food Drug Anala 2002; 10: 178-82.

Di Matteo V, Cacchio M, Di Giulio C, Esposito E. Role of serotonin $_{2 \mathrm{C}}$ receptors in the control of brain dopaminergic function. Pharmacol Biochem Behav 2002; 71: 727-34.

Di Pietro A, Conseil G, Peres-Victoria JM, Dayan G, Baubichon-Cortay $\mathrm{H}$, Trompier $\mathrm{D}$, et al. Modulation by flavonoids of cell multidrug resistance mediated by $\mathrm{P}$-glycoprotein and related $\mathrm{ABC}$ transporters. Cell Mol Life Sci 2002; 59: 307. 
Feng N. Ko, Zhi J. Cheng, Chun N. Lin and Che M. Teng. Scavenger and antioxidant properties of prenylflavones isolated from Artocarpus heterophyllus. Free Radical Bio Med 1998; 25(2): 160-168.

Frankel EN, Waterhouse AL, Teissedre PL. Principal phenolic phytochemicals in selected California wines and their antioxidant activity inhibiting oxidation of human low-density lipoprotein. J. Agric. Food Chem. 1995; 43: 890-4.

Ghani A. Practical Phytochemistry. $1^{\text {st }}$ ed. Parash Publishers, Dhaka, Bangladesh (2005) 12-18.

Gordon $\mathrm{MH}$. The mechanism of antioxidant action in vitro: In B. J. F. Hudson ed. Food antioxidants London: Elsevier Applied Science (1990) 1-18.

Halliwell, B., Gutteridge JM. Role of free radicals and catalytic metal ions in human disease: an overview. Methods Enzymol 1990; 186: $1-85$.

Hemanta Kumar Sharma, Lalrampari Chhangte, Ashoke Kumar Dolui. Traditional medicinal plants in Mizoram, India. Fitoterapia 2001; 72: $146-161$

Hossain MM, Kawamura Y, Yamashita K, Tsukayama, M. Microwave-assisted regioselective synthesis of natural 6-prenylpolyhydroxyisoflavones and their hydrates with hypervalent iodine reagents. Tetrahedron 2006; 62: 8625-35.

Kris-Etherton PM, Harris WS, Appel LJ. Fish consumption, fish oil, omega-3 fatty acids and cardiovascular disease. Circulation 2002; 106: $257-74$.

Kumarasamy Y, Byres M, Cox PJ, Jaspars M, Nahar L, Sarker SD. Screening seeds of some Scottish plants for free-radical scavenging activity. Phytother. Res. 2007; 21: 615-621.

$\mathrm{Li}$ X.M., Wang. Stilbenoids from the lianas of Gnetum pendulum. Phytochemistry 2001; 58: 591-594.

Likhitwitayawuid K., Sritularak B. A New dimeric stilbene with tyrosinase inhibitiory activity from Artocarpus gomezianus. J. Nat. Prod. 2001; 64: 1457-9.

Likhitwitayawuid K., Sritularak B., De-Eknamkul W. Tyrosinase inhibitors from Artocarpus gomezianus. Planta Medica 2000; 66: $275-7$.

Mahato S.B., Banarjee S.K. and Chakravarti R.N. Triterpine of the stem-bark of the Artocarpus chaplasha. Bull Calcutta Sch Trop Med 1967; 15(4): 138-139.

Nomura T., Hano Y., Aida M. Isoprenoid-substituted flavonoids from Artocarpus plants (Moraceae). Heterocycles 1998; 47(2): 11791205.

Oyaizu M. Studies on products of browning reactions. Antioxidative activities of products of browning reaction prepared from glucosamine. Jpn J Nutr 1986; 44: 307-315

Pietta P. Flavonoids as antioxidant. J. Nat. Prod. 2000; 63: 1035-42.

Pin-Der Duh, Yang-Ying Tu and Gow-Chin Yen. Antioxidant activity of the water extract of harn jyur (Chrysanthemum morifolium Ramat). Lebensmittel-Wissenschaft Tech. 1999; 32(5): 269-277.

Resat . A., Kubila G., Mustafa O. and Saliha. E. K. Novel Total Antioxidant Capacity Index for Dietary Polyphenols and Vitamins C and E, Using Their Cupric Ion Reducing Capability in the Presence of Neocuproine: CUPRAC Method. J. Agric. Food Chem. 2004; 52: 7970-81.

Reşat Apak, Kubilay Güçlü, Birsen Demirata, Mustafa Özyürek, Saliha Esin Çelik, Burcu Bektaşoğlu, K. Iș1l Berker and Dilek
Özyurt. Comparative evaluation of various total antioxidant capacity assays applied to phenolic compounds with the CUPRAC Assay. Molecules. 2007; 12: 1496-1547.

Resat Apak, Kubilay Guclu, Mustafa O zyurek, Saliha Esin Celik. Mechanism of antioxidant capacity assays and the CUPRAC (cupric ion reducing antioxidant capacity) assay. Microchim Acta 2008; 160: 413 419.

Serafini M, Bellocco R, Wolk A, Ekstrom AM. Total antioxidant potential of fruit and vegetables and risk of gastric cancer. Gastroenterology 2002; 123: 985-91.

Shailja Sood, Bhawna Arora, Stuti Bansal, Arunachalam Muthuraman, Naresh Singh Gill, Rashmi Arora, Manoj Bali, Pritam Dev Sharma. Antioxidant, anti-inflammatory and analgesic potential of the Citrus decumana L. peel extract. Inflammopharmacol 2009; 17: 267-74.

Sies, H. Oxidative stress: Oxidants and antioxidants. Exp. Physiol. 1997; 82: 291-295.

Soekamto N.H., Achmad S.A., Ghisalberti E.L., Hakim E.H., Syah Y.M.. Artoindonesianins $\mathrm{X}$ and $\mathrm{Y}$, two isoprenylated 2arylbenzofurans, from Artocarpus fretessi (Moraceae). Phytochemistry 2003; 64(4): 831-4.

Su B.N., Cuendet M., Hawthorne M.E., Kardono L.B.S., Riswan S., Fong H.H.S., Mehta R. G., Pezzuto J. M., Kinghorn A. D Constituents of the Bark and Twigs of Artocarpus dadah with cyclooxygenase inhibitory activity. J. Nat. Prod. 2002; 65: 163-9.

Teguo, P.W., Fauconneau. Isolation, identification, andantioxidant activity of three stilbene glucosides newly extracted from Vitis vinifera cell cultures. J. Nat. Prod.1998; 61: 655-657.

Uritani I., Garcia V. V., Mendoza E. M. T. Postharvest biochemistry of plant food- materials in the tropics. $1^{\text {st }}$ ed. Japan Scientific Societies Press, Tokyo, Japan (1994) 241-251.

Vinson JA, Hao Y, Zubic SK. Food antioxidant quantity and quality in foods: Vegetables. J. Agric. Food. Chem. 1998; 46: 3630-3634.

Yong-Hong Wang, Ai-Jun Hou and Dao-Feng Chen. Two New Isoprenylated Stilbenes from Artocarpus chama. J Integr Plant Biol 2007; 49(5): 605-8.

Yong-Hong Wang, Ai-Jun Hou, Dao-Feng Chen, Markus Weiller, Albrecht Wendel and Richard J. Staples. Prenylated Stilbenes and Their Novel Biogenetic Derivatives from Artocarpus chama. Eur. J. Org. Chem. 2006; 15: 3457-63.

Yong-Hong Wang, Ai-Jun Hou, Lei Chen, Dao-Feng Chen, Han-Dong Sun, Qin-Shi Zhao, Kenneth F. Bastow, Yuka Nakanish,, XiHong Wang and Kuo-Hsiung Lee. New Isoprenylated Flavones, Artochamins A-E, and Cytotoxic Principles from Artocarpus chama. J. Nat. Prod. 2004; 67: 757-61.

Yu L, Haley S, Perret J, Harris M, Wilson J, Qian M. Free radical scavenging properties of wheat extracts. J. Agric. Food Chem. 2002; 50: 1619-1624

\section{How to cite this article:}

Taksim Ahmed, Mohammad Nasir Uddin, Shaikh Faisol Ahmed, Arindam Saha, Kaniz Farhana, and Md. Sohel Rana. In vitro evaluation of antioxidant potential of Artocarpus chama Buch fruits . J App Pharm Sci. 2012; 2 (10): 075-080. 